\title{
Cross talks between the immune and lymphatic endothelial cells regulate inflammatory lymph node lymphangiogenesis: defining a new therapeutic approach
}

\author{
Sonia Elhadad \\ From Society for Immunotherapy of Cancer 28th Annual Meeting \\ National Harbor, MD, USA. 8-10 November 2013
}

\section{Introduction}

The lymphatic system serves as the primary route for the metastasis of many cancers and the extent of lymphangiogenesis involvement is the most important indicator of tumor aggressiveness. Despite the apparent importance of the lymphatic vessels for tumor dissemination, it has remained unclear whether immune cells and lymphatic endothelial cells interactions may affect tumor progression and metastasis. Recent evidences indicate regulation of lymph node lymphangiogenesis by $\mathrm{T}$ lymphocytes. However, the nature of the $\mathrm{T}$ cells involved and the nature of the immune response in inflammatory lymph node lymphangiogenesis are still unveiled. We therefore characterized the nature of the inflammatory response in inflammatory lymph node lymphangiogenesis.

\section{Methods}

We used a mouse model of inflammatory lymph node lymphangiogenesis and analyzed the nature of the immune response mounted during lymph node lymphangiogenesis and its role in regulating this pathophysiological process using a combination of flow cytometry, immunohistochemistry, cytokine analysis, and RT-PCR.

\section{Results}

Inflammatory lymph node lymphangiogenesis is a multi step process defined by initiation, expansion and a return to quiescence. We found that each step is tightly orchestrated by a specific $\mathrm{T}$ cell response. At steady state lymph node lymphangiogenesis is negatively regulated by the anti lymphangiogenic cytokine IFN $\gamma$, produced by
CD8 $\alpha \mathrm{T}$ cells. Initiation of inflammatory lymph node lymphangiogenesis results in suppression of CD $8 \alpha$ producing IFN $\gamma \mathrm{T}$ cells and of Th17 cells, and in expansion of Th1 and Th2 cells. Furthermore, inflammatory lymph node lymphangiogenesis is increased in mice deficient in CD4 or CD8 T cells, suggesting a regulating role for each of the $\mathrm{T}$ cell subtypes. The effect of the $\mathrm{T}$ cell on inflammatory lymph node lymphangiogensis is exerted by regulating the production of prolymphangiogenic cytokines.

\section{Conclusion}

Our data suggest that lymphangiogenesis can be targeted therapeutically at different stages, and by different way. This can be a novel strategy to control tumor spread.

Published: 7 November 2013

\section{doi:10.1186/2051-1426-1-S1-P184}

Cite this article as: Elhadad: Cross talks between the immune and lymphatic endothelial cells regulate inflammatory lymph node lymphangiogenesis: defining a new therapeutic approach. Journal for ImmunoTherapy of Cancer 2013 1(Suppl 1):P184.

Memorial Sloan Kettering Cancer Center, New York, NY, USA

(c) 2013 Elhadad; licensee BioMed Central Ltd. This is an Open Access article distributed under the terms of the Creative Commons Attribution License (http://creativecommons.org/licenses/by/2.0), which permits unrestricted use, distribution, and reproduction in any medium, provided the original work is properly cited. 